\title{
What's in a Name? A Lot! Ours Is Now the National Council for Mental Wellbeing
}

\section{Chuck Ingoglia}

Words have power. They can destroy and create. Sometimes words can change everything. ${ }^{1}$

On Wednesday, May 5, 2021, the National Council for Behavioral Health became the National Council for Mental Wellbeing. By changing our name, we are changing the conversation. "Mental wellbeing" means thriving regardless of a mental health or substance use challenge, and it represents resilience, strength, and recovery. Our new name reflects a revitalized vision of making mental wellbeing a core component of comprehensive health and healthcare a reality for all. For more than 50 years as an organization, we have cultivated a mindset of mental wellbeing across five decades of industry-advancing, policy-shaping, and community-building work, one that will guide us for years to come. Moving forward, we will own this phrase.

The name change is not something we entered into lightly. This is a big change, and we have been very deliberate about our transformation. Nothing happened without careful consideration for our members and our board. ${ }^{1}$

But this is much more than just a name change. This is a rebrand! Our new brand reflects our organization's values, vision, market, and purpose. We are realigning how we envision our future progress, not changing our core values but looking ahead to our vital and ever-evolving potential. That future is fast-moving, and we are setting the pace with influential thought leaders as we work with lawmakers to ensure efficient and effective treatment and services.

No doubt, you've already seen our new logo and our new look on our website, our emails, and our publications. It is probably even popped up on your computer screen when you're catching up on current events. It seems like it's everywhere you look. It's hard to miss that brilliant orange. And that's exactly why we chose it. We wanted something that was memorable and as dynamic as the people and organizations we represent. Orange helps us stand out and positions us as a trend setter and thought leader.

Although our name and our look have changed, we remain what we have always been: an organization deeply committed to our members who provide mental health and substance use treatment services

Address correspondence to Chuck Ingoglia, National Council for Mental Wellbeing, Washington, DC, USA. kmenendez@usf.edu.

The Journal of Behavioral Health Services \& Research, 2021. 499-500. (C) 2021, National Council for Mental Wellbeing, . DOI 10.1007/s11414-021-09768-y 
for their communities. Our vision defines the purpose of our organization. It explains how we want to make the world a better place. This is a lofty goal, but everything we do relates to it. If not, then why are we here? We want to make mental wellbeing, including recovery from substance use challenges, a reality for everyone. The words may be a little different, but our vision, our North Star, has never changed.

But a lot has changed over the past year, and we are preparing ourselves to confront new challenges and take advantage of emerging opportunities through the lens of mental wellbeing. The articles in this issue of $J B H S \& R$ reflect this commitment.

As we continue to grapple with the mental health and substance use challenges brought about by a global pandemic, people across our nation have taken to the streets demanding change surrounding systemic racism and its devastating effects. We are taking bold steps to reverse the racially driven inequities that permeate our healthcare systems, but there is a crying need for self-examination. The study by McMaster, Peeples, and Schaffner et al. in this issue of $J B H S \& R$ examining disparities in the care of Black and White clients seeking mental healthcare provides much-needed insight about our current efforts to implement culturally competent care. $^{2}$

One of the most visible changes in mental health and substance use treatment in recent years, one that has been accelerated by the COVID-19 pandemic, is the advent of nontraditional mental healthcare services and tools like mobile apps, peer counselors, and online support groups. No doubt, they've increased access to and utilization of services related to mental wellbeing. But how do they compare to traditional services, especially among tech-savvy adolescents and young adults? The survey by Cohen, Stiles-Shields, and Winquist et al. reported in this issue of $J B H S \& R$ will help us find out. ${ }^{3}$

Individuals recently released from jail or prison with serious mental illnesses face unique vulnerabilities because of the coronavirus pandemic. A study by Barrenger and Bond published in this issue of $J B H S \& R$ aims to increase understanding of how they experienced the pandemic during initial stay-at-home orders in New York City and ways they coped with changes to their services, including suspensions of some supportive services. The results will help us understand how comprehensive reentry services may need to be adapted to address the multiple needs of individuals and to facilitate community reintegration. ${ }^{4}$

Today, the work of mental health and substance use treatment organizations is more important than ever. Our challenge is to ensure that everyone has access to comprehensive, high-quality, and affordable treatment when they need it. By promoting comprehensive approaches to prevention, treatment, and recovery supports, we will ensure mental wellbeing is a reality for everyone.

As we move forward, we strive to make the National Council for Mental Wellbeing a household name.

\section{References}

1. Compassion International. The power of words. Available online at https://www.compassion.com/letter-writing/the-power-of-words.htm\#: : text=Words $\% 20$ have $\% 20$ power.,They $\% 20$ can $\% 20$ destroy $\% 20$ and $\% 20$ create.\&text $=$ We $\% 20$ can $\% 20$ choose $\% 20$ to $\% 20$ use,to $\% 20$ humiliate $\%$ 20 and\%20to\%20humble.\%E2\%80\%9D. Accessed on July 14, 2021.

2. McMaster KJ, Peeples AD, Schaffner RM, et al. Mental healthcare provider perceptions of race and racial disparity in the care of Black and White clients. Journal of Behavioral Health Services \& Research. 2021;48(4). https://doi.org/10.1007/s11414-019-09682-4

3. Cohen K, Stiles-Shields C, Winquist N, et al. Traditional and nontraditional mental healthcare services: usage and preferences among adolescents and younger adults. Journal of Behavioral Health Services \& Research. 2021;48(4). https://doi.org/10.1007/s11414-020-09746-w

4. Barrenger SL, Bond L. Mental health and service impacts during COVID-19 for individuals with serious mental illnesses recently released from prison and jail. Journal of Behavioral Health Services \& Research. 2021;48(4). https://doi.org/10.1007/s11414-021-09759-Z

Publisher's Note Springer Nature remains neutral with regard to jurisdictional claims in published maps and institutional affiliations. 